\title{
Somatic USP8 mutations are frequent events in corticotroph tumor progression causing Nelson's tumor
}

\author{
Luis G Pérez-Rivas1,*, Marily Theodoropoulou1,2, *, Troy H Puar3,4, Julia Fazel', Mareike R Stieg², \\ Francesco Ferraù, , Guillaume Assié6 ${ }^{6}$ Monica R Gadelha7, Timo Deutschbein ${ }^{8}$, Maria C Fragoso ${ }^{9}$, \\ Benno Kusters ${ }^{10}$, Wolfgang Saeger ${ }^{11}$, Jürgen Honegger ${ }^{12}$, Michael Buchfelder ${ }^{13}$, Márta Korbonits ${ }^{5}$, \\ Jérôme Bertherat ${ }^{6}$, Günter K Stalla ${ }^{2}$, Ad R Hermus ${ }^{3}$, Felix Beuschlein ${ }^{1,14}$ and Martin Reincke ${ }^{1}$
}

${ }^{1}$ Medizinische Klinik und Poliklinik IV, Ludwig-Maximilians-Universität München, Munich, Germany, ${ }^{2}$ Clinical Neuroendocrinology, Max Planck Institute of Psychiatry, Munich, Germany, ${ }^{3}$ Department of Internal Medicine, Division of Endocrinology, Radboud University Medical Centre, Nijmegen, The Netherlands, ${ }^{4}$ Department of Endocrinology, Changi General Hospital, Singapore, Singapore, ${ }^{5}$ Centre for Endocrinology, William Harvey Research Institute, Barts and The London School of Medicine and Dentistry, Queen Mary University of London, London, UK, ${ }^{6}$ Department of Endocrinology, Cochin Hospital, Assistance Publique Hôpitaux de Paris; Inserm Unité 1016, Centre National de la Recherche Scientifique Unité Mixte de Recherche, Institut Cochin, Université Paris Descartes, Paris, France, ${ }^{7}$ Division of Endocrinology, Hospital Universitário Clementino Fraga Filho, Universidade Federal do Rio de Janeiro, Rio de Janeiro, Brazil, ${ }^{8}$ Division of Endocrinology and Diabetology, Department of Internal Medicine, University Hospital Würzburg, University of Würzburg, Würzburg, Germany, ${ }^{9}$ Unidade de Neuroendocrinologia, Laboratório de Hormônios e Genética Molecular/LIM42, Disciplina de Endocrinologia e Metabologia, Hospital das Clínicas da Faculdade de Medicina da Universidade de São Paulo, São Paulo, Brasil, ${ }^{10}$ Department of Pathology, Radboud University Medical Centre, Nijmegen, The Netherlands, ${ }^{11}$ Institut für Neuropathologie der Universität Hamburg, Hamburg, Germany, ${ }^{12}$ Department of Neurosurgery, Eberhard Karls University Tübingen, Tübingen, Germany, ${ }^{13}$ Neurochirurgische Klinik, Klinikum der Universität Erlangen, Erlangen, Germany, and ${ }^{14} \mathrm{~K}$ linik für Endokrinologie, Diabetologie und Klinische Ernährung, Universitätsspital Zürich, Zürich, Switzerland

*(L G Pérez-Rivas and M Theodoropoulou contributed equally to this work)

Correspondence should be addressed to $\mathrm{M}$ Theodoropoulou Email marily.theodoropoulou@ med.uni-muenchen.de

\begin{abstract}
Objective: Somatic mutations in the ubiquitin-specific protease 8 (USP8) gene are frequent in corticotroph tumors causing Cushing's disease (CD). Corticotroph tumor progression, the so-called Nelson's syndrome (NS), is a potentially life-threatening complication of bilateral adrenalectomy in patients with refractory CD that is caused by the development of an ACTH-secreting tumor of the pituitary gland. Whether USP8 alterations are also present in progressive Nelson's tumors has not been studied in detail so far.
\end{abstract}

Design and Methods: Retrospective, multicenter study involving tumors from 33 patients with progressive corticotroph tumors (29 females) and screening for somatic mutations on the mutational hotspot of the USP8 gene in the exon 14 with Sanger sequencing.

Results: Fifteen out of 33 tumors (45\%) presented with a mutation in the exon 14 of USP8, with c.2159C>A (p.Pro720Gln) being the most frequent (9/33), followed by c.2155_2157delTCC (p.Ser718del, 4/33) and c.2152T>C (p.Ser718Pro, 2/33). This prevalence is similar to that previously reported for CD. Mutations were found exclusively in females. Other variables, such as age at diagnosis with NS, body mass index, hyperpigmentation, visual field defects, adenoma size or mortality, did not significantly differ between patients with wild-type and mutant tumors. Patients with USP8 mutant tumors exhibited higher levels of plasma ACTH after surgery (median: 640 vs $112 \mathrm{pg} / \mathrm{mL}, P=0.03$ ). No differences were observed in ACTH normalization $(<50 \mathrm{pg} / \mathrm{mL})$ and tumor control after surgery for Nelson's tumor. Conclusion: Somatic mutations in USP8 are common in Nelson's tumors, indicating that they do not drive the corticotroph tumor progression that leads to NS, and may be associated with a less favorable biochemical outcome after surgery for Nelson's tumor. Printed in Great Britain
Published by Bioscientifica Ltd. 


\section{Introduction}

Bilateral adrenalectomy is an effective and relatively safe procedure to control hypercortisolism in patients with Cushing's disease (CD) when surgery and other therapies failed or are not applicable (1). In addition to a lifelong hormone replacement, patients need an extensive follow-up due to the risk of developing corticotroph tumor progression also known as Nelson's syndrome (NS). NS is a potentially life-threatening complication caused by the growth of a functional corticotroph tumor after bilateral adrenalectomy, which is generally considered a progression of the initial corticotroph adenoma (2). Tumors causing NS can be aggressive as well as refractory to different therapies and, in some cases, can evolve to pituitary carcinomas $(3,4)$.

Frequent clinical manifestations are cutaneous hyperpigmentation due to an excess of proopiomelanocortin derivatives, as well as headache, visual defects and cranial nerve palsy due to tumor enlargement and compression. However, not all symptoms are presented in each NS case $(5,6)$ and thus there is a lack of consensus both on the definition and the diagnostic criteria of NS $(5,7,8,9)$. Of note, it has also been suggested to replace NS by the term corticotroph tumor progression since incident tumor growth can be identified in up to $50 \%$ of the patients after modern MRI imaging years before hyperpigmentation develops (7).

The prevalence of the syndrome is variable, ranging between 8 and $29 \%$ of CD patients that undergo bilateral adrenalectomy. Furthermore, it presents a wide time interval in its onset, from few months to more than 10 years after adrenalectomy (2). Accordingly, a lifelong close follow-up is recommended for early detection of NS $(7,10)$, thereby pointing to the need of disease and outcome markers as well as new molecular candidates for targeted therapies. It is not clear whether corticotroph tumor progression is the consequence of a more aggressive tumor behavior or the complete loss of glucocorticoid feedback after bilateral adrenalectomy. To date, only rare somatic alterations have been described in Nelson's tumors $(11,12)$ and there is a lack of information about the molecular processes underlying the development of the syndrome.

Recently, the gene coding for the ubiquitin-specific protease 8 (USP8) has been identified to play a remarkable role in the pathogenesis of CD. USP8 is mutated in approximately $50 \%$ of pituitary adenomas causing $\mathrm{CD}$ (13). So far, all USP8 mutations in CD tumors are located in a single mutational hotspot in exon $14(14,15,16,17)$. The resulting USP8 mutants show higher activity than the wild-type and trigger ACTH secretion in pituitary cells through EGFR-dependent signaling (17). It is noteworthy that USP8 mutations represent an exclusive trait of $\mathrm{CD}$ and are not detected in any other type of pituitary tumors nor in ACTH-producing tumors of extrapituitary origin $(15,16,17,18,19,20)$. The aim of this study is to investigate the mutational status of USP8 in tumors of patients diagnosed with NS.

\section{Subjects and methods}

\section{Patients and samples}

This study was approved by the Ethics Committee of each participating institution and in compliance with the Declaration of Helsinki. All patients gave written informed consent after full explanation of the purpose and nature of all procedures used. We assembled a cohort of 41 tumor samples (33 Nelson's tumors and 8 original CD) originating from 33 patients treated in 7 participating centers in Europe and Brazil. Patients were included in our study according to the definition of NS given by Barber et al. (8): diagnosis of CD and, after undergoing bilateral adrenalectomy, development of a pituitary mass expanding in size and/or an increase of the levels of plasma ACTH $>500 \mathrm{pg} / \mathrm{mL}$ with progressive elevations of $>30 \%$ on at least three consecutive occasions. When available, we also studied the initial CD tumor in addition to the Nelson tumor $(n=8)$. Basal ACTH was defined as the levels of plasma ACTH at the time of diagnosis of CD. Pre- and postoperative measurements referred only to the surgery in which Nelson's tumor was collected, at least $20 \mathrm{~h}$ after the last administration of glucocorticoid. ACTH normalization was defined as postoperative plasma levels $<50 \mathrm{pg} / \mathrm{mL}$. Tumor control was defined as lack of adenoma growth and absence of recurrence.

\section{DNA extraction and sequencing}

Genomic DNA was extracted from 20 fresh-frozen and 21 FFPE corticotroph tumors using the Maxwell Tissue DNA Kit (Promega) or the FFPE DNA mini kit (Qiagen), respectively. The DNA sequence corresponding to the exon 14 of USP8 was amplified with the GoTaq DNA polymerase (Promega) and sequenced by means of Sanger sequencing as described previously (14). The chromatograms were analyzed using the Mutation Surveyor software v4.0.9 (Soft Genetics). 


\section{Statistical analysis}

Statistical analysis was performed with the software package SPSS v23 (IBM). Nominal variables were compared using $\chi^{2}$ or Fisher exact test when needed. Mann-Whitney $U$ test and Kruskal-Wallis test were used for the analysis of non-parametric variables, such as age, time intervals and plasma levels of ACTH. Wilcoxon signed ranks and Friedman test were used to study ACTH variations over time in wild-type and mutant groups separately. Correction for multiple comparisons was performed by means of the Dunn-Bonferroni test. A $t$-test was used to assess the effects of mutations on tumor size and body mass index. Categorical variables were analyzed using a Chi-square test. An exact, two-tailed significance level of $P<0.05$ was considered to be statistically significant.

\section{Results}

To investigate the presence of USP8 mutations in tumors of patients with NS, we sequenced the exon 14 of USP8 in tumors from a cohort of 33 patients, 4 males and 29 females. Fifteen cases have been reported elsewhere $(3,12$, 21). Except for one case, all patients in our series presented with hyperpigmentation. Transsphenoidal surgery was the treatment of choice for $\mathrm{CD}$ in 20 patients, whereas 12 underwent bilateral adrenalectomy without any previous treatment.

In 15 out of 33 patients (45.5\%), we found somatic USP8 mutations in Nelson's tumors. This proportion is similar to that reported for CD (47.3\%; Fig. 1) $(14,15$, 16 , 17). The substitution c. $2159 \mathrm{C}>\mathrm{A}$ (p.Pro720Arg) was the most frequent alteration (9/33 cases, $27.3 \%)$. Other mutations were c.2155_2157delTCC (p.Ser718del) in $4 / 33$ cases (12.1\%) and c.2152T >C (p.Ser718Pro) in 2/33 cases $(6.1 \%)$. We could obtain the original tumor prior to the bilateral adrenalectomy (i.e. the CD tumor) from
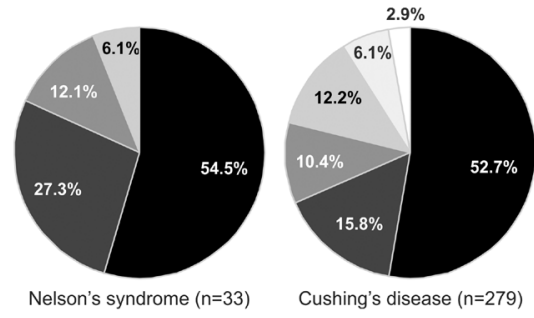

- Wild-type

- $\mathrm{c} .2159 \mathrm{C}>\mathrm{A}$ (p.Pro720Arg)

a.2155_2157delTCC (p.Ser718del)

$\square$ c.2152T>C (p.Ser718Pro)

$\square$ Other point mutations

$\square$ Other deletions

\section{Figure 1}

Prevalence of USP8 mutations in Nelson's syndrome (left) and Cushing's disease (right). Data on CD were obtained from references $(14,15,16,17)$.
8 cases. Within those 8 paired Cushing's/Nelson's tumors, 4 pairs were wild-type and 2 were mutant ( 2 deletions p.Ser718del), while the remaining two pairs consisted of wild-type CD tumors with USP8 mutant NS tumors (p.Pro720Arg and p.Ser718del). Pathological investigation did not identify tumor part in these two CD specimens suggesting that what we analyzed was in fact non-tumor pituitary tissue.

We excluded three cases from subsequent statistical analyses. First, a female patient with c.2159C $>$ A (p.Pro720Arg) mutation was also found to have the germline AIP variant c.911G >A (p.Arg304Gln) (22). This patient had a recurrent NS tumor and was operated twice. The USP8 mutation c.2159C >A (p.Pro720Arg) was detected in the NS tumor specimens from both operations. Second, a male patient with wild-type USP8 had a somatic mutation in TP53 acquired after radiotherapy (12). Third, a female patient with wild-type USP8 status had an invasive adenoma that progressed to a pituitary carcinoma with metastasis in the dura (3).

USP8 mutations were detected exclusively in female patients $(14 / 27 ; 51.9 \%)$. No significant association was observed between USP8 mutational status and most clinical and pathological parameters (Table 1). The time lapse between age at diagnosis of CD and NS tended to be longer in females with tumors positive for USP8 mutation (median 13 vs 5 years; $P=0.097 ; n=26$; Supplementary Table 1 , see section on supplementary data given at the end of this article). We did not observe differences in the distribution of patients treated with radiotherapy $(n=24)$; from the 13 patients with wild-type tumors, 9 were treated with radiotherapy (3 pre- and 6 postoperatively), and from the 12 patients with USP 8 mutant tumors, 7 were treated with radiotherapy ( 2 pre- and 5 postoperatively). Regarding the hormonal phenotype, the pairwise analysis showed that the postoperative levels of ACTH were higher in patients with USP8 mutant tumors (639.8 vs $112.0 \mathrm{pg} /$ $\mathrm{mL}$; Mann-Whitney $U, P=0.03 ; n=23$; Table 1$)$. We compared ACTH dynamics at the three given times (basal, preoperative and postoperative) in each group by means of Kruskal-Wallis and Friedman's tests corrected for multiple comparisons and we observed that the levels of plasma ACTH decreased significantly after NS surgery in the group of patients with USP8 wild-type tumors (Mann-Whitney $U$ for independent measurements, $P<0.001$; Wilcoxon signed ranks for repeated measurements, $P=0.001$; Fig. 2) but not in the USP8 mutant group (Mann-Whitney $U$, $P=0.999$; Wilcoxon signed ranks sums, $P=0.283$ ). ACTH normalization was achieved only in few patients regardless of USP8 status ( $3 / 13$ vs $1 / 10, P=0.604 ; n=23)$. 
Table 1 Clinical features and USP8 mutational status.

\begin{tabular}{l} 
Sex, $n$ (\%) \\
Females \\
Males \\
Age, years, median (IQR) \\
At diagnosis of CD \\
At BADx \\
At diagnosis of NS \\
Time interval, years, median (IQR) \\
From CD to NS \\
From CD to BADx \\
From BADx to NS \\
Body mass index, kg/m², mean (s.D.) \\
Hyperpigmentation, $n(\%)$ \\
Visual field defects, $n(\%)$ \\
Cranial nerve palsy, $n(\%)$ \\
Plasma ACTH, pg/mL, median (IQR) \\
Basal \\
Preoperative ${ }^{1}$ \\
Postoperative \\
ACTH normalization (<50 pg/mL), $n(\%)$ \\
Radiation therapy, $n(\%)$ \\
Before sample collection \\
After sample collection \\
Number of sellar surgeries before BADx, $n(\%)$ \\
0 \\
1 \\
2 \\
T2 \\
Tumber of sellar surgeries after BADx, $n(\%)$ \\
Tumor control, $n$ (\%) \\
Disease-related death, $n(\%)$ \\
\hline
\end{tabular}

\begin{tabular}{c}
\hline Study cohort \\
\hline \\
$27 / 30(90.0)$ \\
$3 / 30(10.0)$ \\
\\
$30.0(7.0)$ \\
$34.0(13.0)$ \\
$42.0(16.0)$ \\
\\
$8.0(13.8)$ \\
$1.0(3.8)$ \\
$5.0(8.0)$ \\
$26.1(5.3)$ \\
$25 / 27(92.6)$ \\
$6 / 27(22.2)$ \\
$6 / 26(23.1)$ \\
$100.0(334.2)$ \\
$1545.4(6816.8)$ \\
$204.6(620.5)$ \\
$4 / 23(17.4)$ \\
$5 / 25(20.0)$ \\
$11 / 25(44.0)$ \\
$11 / 29(37.9)$ \\
$11 / 29(37.9)$ \\
$6 / 29(20.7)$ \\
$1 / 29(3.5)$ \\
$21 / 27(77.8)$ \\
$3 / 27(11.1)$ \\
$3 / 27(11.1)$ \\
$18.6(9.6)$ \\
$18 / 24(0.75)$ \\
$4 / 27(16.7)$ \\
\hline
\end{tabular}

\begin{tabular}{c}
\hline Wild-type \\
\hline $13 / 27(48.1)$ \\
$3 / 3(100.0)$ \\
$31.0(8.0)$ \\
$35.0(17.0)$ \\
$42.0(21.0)$ \\
$5.0(14.0)$ \\
$0.5(4.0)$ \\
$4.5(7.3)$ \\
$26.9(5.4)$ \\
$12 / 14(85.7)$ \\
$4 / 14(28.6)$ \\
$4 / 13(30.8)$ \\
$104.7(158.6)$ \\
$1261.0(2381.5)$ \\
$112.0(251.8)$ \\
$3 / 13(23.1)$ \\
$3 / 13(23.1)$ \\
$6 / 13(46.2)$ \\
$5 / 15(33.3)$ \\
$8 / 15(53.3)$ \\
$2 / 15(13.3)$ \\
$0 / 15(0.0)$ \\
$9 / 13(69.2)$ \\
$2 / 13(15.4)$ \\
$2 / 13(15.4)$ \\
$18.6(10.5)$ \\
$9 / 13(69.2)$ \\
$3 / 15(20.0)$ \\
\end{tabular}

\begin{tabular}{|c|c|}
\hline Mutant & $P$ value \\
\hline $\begin{array}{c}14 / 27(51.9) \\
0 / 3(0.0)\end{array}$ & 0.228 \\
\hline $\begin{array}{l}30.0(7.0) \\
32.0(10.0) \\
43.0(14.0)\end{array}$ & $\begin{array}{l}0.403 \\
0.680 \\
0.723\end{array}$ \\
\hline $\begin{array}{c}12.0(13.0) \\
1.0(3.3) \\
5.0(10.0) \\
25.4(5.4) \\
13 / 13(100.0) \\
2 / 13(15.4) \\
2 / 13(15.4)\end{array}$ & $\begin{array}{l}0.144 \\
0.722 \\
0.617 \\
0.617 \\
0.481 \\
0.648 \\
0.645\end{array}$ \\
\hline $\begin{array}{c}100.0(1353.0) \\
1700.0(11115.5) \\
639.8(1706.5) \\
1 / 10(10.0)\end{array}$ & $\begin{array}{l}0.349 \\
0.072 \\
0.030 \\
0.604\end{array}$ \\
\hline $\begin{array}{l}2 / 12(16.7) \\
5 / 12(41.7) \\
\\
6 / 14(42.9) \\
3 / 14(21.4) \\
4 / 14(28.6) \\
1 / 14(7.1)\end{array}$ & $\begin{array}{l}1.000 \\
1.000 \\
0.299\end{array}$ \\
\hline $\begin{array}{c}12 / 14(85.8) \\
1 / 14(7.1) \\
1 / 14(7.1)\end{array}$ & 0.683 \\
\hline $\begin{array}{l}18.6(9.3) \\
9 / 11(82.8) \\
1 / 12(8.3)\end{array}$ & $\begin{array}{l}0.970 \\
0.410 \\
0.605\end{array}$ \\
\hline
\end{tabular}

BADx, bilateral adrenalectomy.

a $P$ values generated from Mann-Whitney $U$ pairwise analysis. Bold value indicates statistical significance $(P<0.05)$

\section{Discussion}

In this study, we report for the first time the presence of somatic genetic defects in a large series of patients with NS tumors. In our cohort, almost half of the NS tumors contained somatic mutations in USP8, all of them causing substitution or deletion of the residues Ser718 or Pro720. This prevalence $(45.5 \%)$ is similar to that observed in CD tumors (47.3\%) in which the wide majority of the identified mutations affects the residues Ser718, Pro720 or both $(14,15,16,17)$. Similarly, the gender-specific distribution of mutations showed a female predominance for both CD and NS. In detail, half of the female patients presented tumors with USP8 mutations, a frequency that resembles that observed for $C D(14,15,16,17)$. These similarities as well as the consistency in the USP 8 mutational status between paired $\mathrm{CD} / \mathrm{NS}$ samples strongly support the hypothesis of NS tumors as a progression or a recurrence of the initial CD tumor $(2,8)$. However, the same prevalence of USP8 mutations between CD and NS tumors makes it unlikely that these mutations trigger the progression from Cushing's to Nelson's tumor.

Previous studies on CD have reported significant associations between USP8 mutations and a younger age at diagnosis in female patients, smaller tumor size, higher basal levels of plasma ACTH and higher postoperative levels of urinary-free cortisol $(13,14,15,16,17)$. We did not observe any association with these variables in our series of NS, probably due to the cohort size as well as the retrospective and multicentric nature of the study. Nevertheless, we did observe a significantly impaired reduction in plasma ACTH after NS surgery in patients with USP8 mutated tumors. Postoperative hormone 


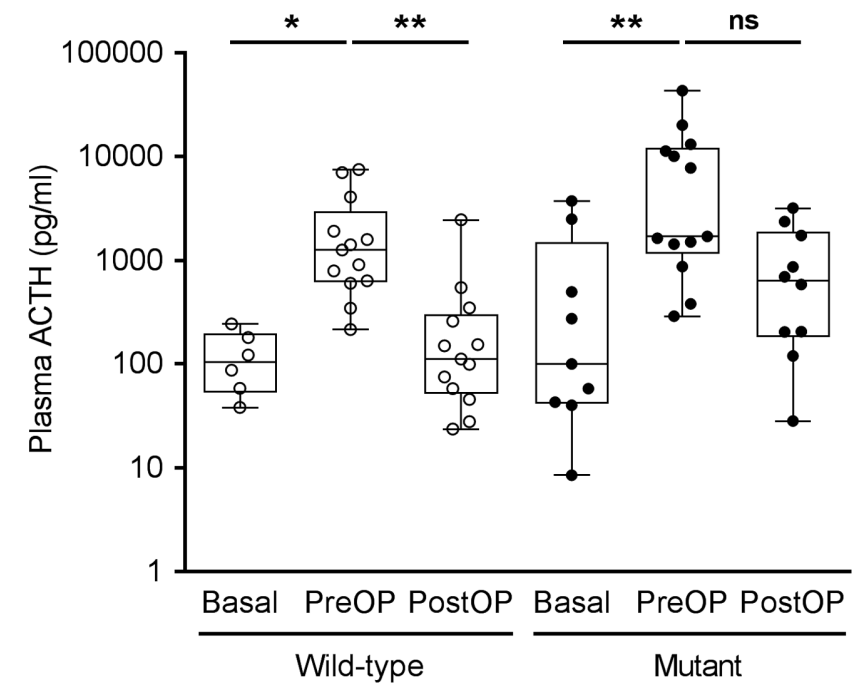

Figure 2

Dynamics of plasma ACTH in patients with Nelson's syndrome with and without USP8 mutations. Plasma ACTH was measured at the time of diagnosis with $C D$ (basal), before (PreOP) and after the NS surgery (PostOP). Values are shown in a logarithmic scale. Lines represent the medians, boxes the 25th and 75th percentiles and whiskers the ranges of the distribution. ${ }^{*} P<0.05 ;{ }^{*} P<0.001$; ns not significant. Statistical analysis revealed different ACTH dynamics within the wildtype group (basal vs PreOP, $P=0.028$; PreOP vs PostOP, $P<0.001$ ) and the USP8 mutant group (basal vs PreOP, $P<0.001$; PreOP vs PostOP, $P=0.2565$ ) after correction for multiple comparisons. The differences between wild-type and mutants at basal $(P=1.000)$, PreOP $(P=1.000)$ and PostOP ACTH levels $(P=0.630)$ were not significant.

levels have been proposed as prognostic markers for surgical outcome, with several studies showing that low postoperative ACTH and cortisol levels are related to longterm remission and lower recurrence rates in CD $(23,24$, $25,26,27)$. Therefore, the presence of USP8 mutations may predict a worse postoperative phenotype.

Interestingly, in our cohort, we detected a somatic USP8 mutation in a 27-year-old patient with an associated germline AIP variant c.911G>A (p.Arg304Gln). The patient showed early manifestation and rapid progression of the disease with the NS tumor being resected twice (22). The p.Arg304Gln variant has been seen as pathogenic from a clinical point of view, but according to the in vitro studies, it is considered a variant of unknown significance (28). This is the first reported case of a USP8 mutant tumor associated with a germline $A I P$ alteration. Since CD is rarely seen in patients with germline AIP mutation $(29,30,31,32,33,34,35)$, one may hypothesize that the acquisition of a somatic USP8 mutation in this patient may have shifted toward the development of a corticotroph tumor.

This patient was treated with the second-generation multireceptor targeting somatostatin analog pasireotide and showed reduction in plasma ACTH and substantial improvement of symptoms after 6 months of treatment (22). This is in agreement with another study reporting good response to pasireotide treatment in patients with NS, thereby providing the rationale for their use in the management of corticotroph tumors $(22,36)$. The recent report of a direct relationship between USP8 mutational status and somatostatin receptor 5 (SSTR5) expression (37) suggests that patients with USP8 mutation positive corticotroph tumors may respond favorably to pasireotide treatment.

In conclusion, in this multicenter study we found that USP8 mutations are common in NS tumors, showing a comparable prevalence to CD tumors. Similar to CD, there is a striking female predominance and an association with a worse postoperative outcome. Taken together, our data indicate that the USP8 mutational status does not drive the corticotroph tumor progression that leads to NS. Hence, other yet-to-be-identified genetic alterations may determine the development of this aggressive tumor entity.

Supplementary data

This is linked to the online version of the paper at https://doi.org/10.1530/ EJE-17-0634.

\section{Declaration of interest}

The authors declare that there is no conflict of interest that could be perceived as prejudicing the impartiality of the research reported.

\section{Funding}

The work was supported by the Else Kröner-Fresenius-Stiftung (grant \# 2012 A103 and 2015_A228 to M R) and the Deutsche Forschungsgemeinschaft within the CRC/Transregio 205/1 'The Adrenal: Central Relay in Health and Disease' to M R and M T. L G P R is supported by a grant from the Deutsche Forschungsgemeinschaft (DFG, grant \# RE 752/20-1). T D received a research grant from the Interdisciplinary Center for Clinical Research (IZKF) of the University of Würzburg (grant number Z-2/57). The research leading to these results has received funding from the People Programme (Marie Curie Actions) of the European Union's Seventh Framework Programme (FP7/2007-2013) under REA grant agreement no. 608765 (L G P R) and by a research grant from the Medical Research Grant, UK and from Pfizer (M $\mathrm{K})$. The funder institutions had no role in the design and conduct of the study; collection, management, analysis and interpretation of the data; preparation, review or approval of the manuscript or decision to submit the manuscript for publication. 


\section{Acknowledgements}

The authors thank Brigitte Mauracher for excellent technical assistance.

\section{References}

1 Reincke M, Ritzel K, Oßwald A, Berr C, Stalla G, Hallfeldt K, Reisch N, Schopohl J \& Beuschlein F. A critical reappraisal of bilateral adrenalectomy for ACTH-dependent Cushing's syndrome. European Journal of Endocrinology 2015173 M23-M32. (https://doi. org/10.1530/EJE-15-0265)

2 Assié G, Bahurel H, Bertherat J, Kujas M, Legmann P \& Bertagna X. The Nelson's syndrome ... revisited. Pituitary 20057 209-215. (https://doi.org/10.1007/s11102-005-1403-y)

3 Kemink SA, Wesseling P, Pieters GF, Verhofstad AA, Hermus AR \& Smals AG. Progression of a Nelson's adenoma to pituitary carcinoma; a case report and review of the literature. Journal of Endocrinological Investigation 199922 70-75. (https://doi.org/10.1007/BF03345482)

4 Pimentel-Filho FR, Cukiert A, Miyashita F, Huayllas MK, Knoepfelmacher M, Salgado LR \& Liberman B. Adrenocorticotropin levels do not change during early recovery of transsphenoidal surgery for ACTH-secreting pituitary tumors. Journal of Endocrinological Investigation 200124 83-87. (https://doi.org/10.1007/ BF03343818)

5 Ritzel K, Beuschlein F, Mickisch A, Osswald A, Schneider HJ, Schopohl J \& Reincke M. Clinical review: outcome of bilateral adrenalectomy in Cushing's syndrome: a systematic review. Journal of Clinical Endocrinology and Metabolism 201398 3939-3948. (https:// doi.org/10.1210/jc.2013-1470)

6 Graffeo CS, Perry A, Carlstrom LP, Meyer FB, Atkinson JLD, Erickson D, Nippoldt TB, Young WF, Pollock BE \& Van Gompel JJ. Characterizing and predicting the Nelson-Salassa syndrome. Journal of Neurosurgery 2017 1-11. (https://doi.org/10.3171/2016.9. JNS161163)

7 Assié G, Bahurel H, Coste J, Silvera S, Kujas M, Dugué MA, Karray F, Dousset B, Bertherat J, Legmann P et al. Corticotroph tumor progression after adrenalectomy in Cushing's Disease: a reappraisal of Nelson's Syndrome. Journal of Clinical Endocrinology and Metabolism 200792 172-179. (https://doi.org/10.1210/jc.2006-1328)

8 Barber TM, Adams E, Ansorge O, Byrne JV, Karavitaki N \& Wass JAH. Nelson's syndrome. European Journal of Endocrinology/European Federation of Endocrine Societies 2010163 495-507. (https://doi. org/10.1530/EJE-10-0466)

9 Palermo NE \& Ananthakrishnan S. Re-examining Nelson's syndrome. Current Opinion in Endocrinology and Diabetes and Obesity 201522 313-318. (https://doi.org/10.1097/MED.0000000000000175)

10 Ayala A \& Manzano AJ. Detection of recurrent Cushing's disease: proposal for standardized patient monitoring following transsphenoidal surgery. Journal of Neuro-oncology 2014119 235-242. (https://doi.org/10.1007/s11060-014-1508-0)

11 Karl M, Von Wichert G, Kempter E, Katz DA, Reincke M, Mönig H, Ali IU, Stratakis CA, Oldfield EH, Chrousos GP et al. Nelson's syndrome associated with a somatic frame shift mutation in the glucocorticoid receptor gene. Journal of Clinical Endocrinology and Metabolism 199681 124-129. (https://doi.org/10.1210/ jcem.81.1.8550738)

12 Pinto EM, Siqueira SA, Cukier P, Fragoso MCBV, Lin CJ \& DeMendonca BB. Possible role of a radiation-induced p53 mutation in a Nelson's syndrome patient with a fatal outcome. Pituitary 2011 14 400-404. (https://doi.org/10.1007/s11102-009-0194-y)

13 Perez-Rivas LG \& Reincke M. Genetics of Cushing's disease: an update. Journal of Endocrinological Investigation 201639 29-35. (https://doi.org/10.1007/s40618-015-0353-0)

14 Perez-Rivas LG, Theodoropoulou M, Ferraù F, Nusser C, Kawaguchi K, Stratakis CA, Rueda Faucz F, Wildemberg LE, Assié G, Beschorner R et al. The gene of the ubiquitin-specific protease 8 is frequently mutated in adenomas causing Cushing's disease. Journal of Clinical Endocrinology and Metabolism 2015100 E997-E1004. (https://doi. org/10.1210/jc.2015-1453)

15 Ma ZY, Song ZJ, Chen JH, Wang YF, Li SQ, Zhou LF, Mao Y, Li YM, $\mathrm{Hu}$ RG, Zhang ZY et al. Recurrent gain-of-function USP8 mutations in Cushing's disease. Cell Research 201525 1-12. (https://doi. org/10.1038/cr.2015.20)

16 Song ZJ, Reitman ZJ, Ma ZY, Chen JH, Zhang QL, Shou XF, Huang CX, Wang YF, Li SQ, Mao Y et al. The genome-wide mutational landscape of pituitary adenomas. Cell Research $2016 \mathbf{1 0}$ 1-5. (https://doi.org/10.1038/cr.2016.114)

17 Reincke M, Sbiera S, Hayakawa A, Theodoropoulou M, Osswald A, Beuschlein F, Meitinger T, Mizuno-Yamasaki E, Kawaguchi K, Saeki Y et al. Mutations in the deubiquitinase gene USP8 cause Cushing's disease. Nature Genetics 201547 31-38. (https://doi.org/10.1038/ ng.3166)

18 Trivellin G, Correa RR, Batsis M, Faucz FR, Chittiboina P, Bjelobaba I, Larco DO, Quezado M, Daly AF, Stojilkovic SS et al. Screening for GPR101 defects in pediatric pituitary corticotropinomas. EndocrineRelated Cancer 201623 357-365. (https://doi.org/10.1530/ERC-160091)

19 Ronchi CL, Peverelli E, Herterich S, Weigand I, Mantovani G, Schwarzmayr T, Sbiera S, Allolio B, Honegger J, Appenzeller S et al. Landscape of somatic mutations in sporadic GH-secreting pituitary adenomas. European Journal of Endocrinology 2016174 363-372. (https://doi.org/10.1530/EJE-15-1064)

20 Pérez-Rivas LG, Oßwald A, Knösel T, Lucia K, Schaaf C, Hristov M, Fazel J, Kirchner T, Beuschlein F, Reincke $\mathrm{M}$ et al. Expression and mutational status of USP8 in tumors causing ectopic ACTH secretion syndrome. Endocrine-Related Cancer 201724 L73-L77. (https://doi. org/10.1530/ERC-17-0054)

21 Kemink SA, Grotenhuis JA, De Vries J, Pieters GF, Hermus ARMM \& Smals AG. Management of Nelson's syndrome: observations in fifteen patients. Clinical Endocrinology 200154 45-52. (https://doi. org/10.1046/j.1365-2265.2001.01187.x)

22 Stieg M, Auer M, Dimopoulou C, Athanasoulia A \& Stalla G. First report of an AIP mutation in Nelson's syndrome successfully treated with the novel multireceptor-targeted somatostatin analogue pasireotide (SOM230). Experimental and Clinical Endocrinology and Diabetes 2013121 22. (https://doi.org/10.1055/s-0033-1359457)

23 Pereira AM, Van Aken MO, Van Dulken H, Schutte PJ, Biermasz NR, Smit JW, Roelfsema F \& Romijn JA. Long-term predictive value of postsurgical cortisol concentrations for cure and risk of recurrence in Cushing's disease. Journal of Clinical Endocrinology and Metabolism 200388 5858-5864. (https://doi.org/10.1210/jc.2003-030751)

24 Patil CG, Prevedello DM, Lad SP, Vance ML, Thorner MO, Katznelson L \& Laws ER. Late recurrences of Cushing's disease after initial successful transsphenoidal surgery. Journal of Clinical Endocrinology and Metabolism 200893 358-362. (https://doi. org/10.1210/jc.2007-2013)

25 Dimopoulou C, Schopohl J, Rachinger W, Buchfelder M, Honegger J, Reincke M \& Stalla GK. Long-term remission and recurrence rates after first and second transsphenoidal surgery for Cushing's disease: care reality in the munich metropolitan region. European Journal of Endocrinology 2014170 283-292. (https://doi.org/10.1530/EJE-130634)

26 Sonino N, Zielezny M, Fava GA, Fallo F \& Boscaro M. Risk factors and long-term outcome in pituitary-dependent Cushing's disease. Journal of Clinical Endocrinology and Metabolism 199681 2647-2652. (https:// doi.org/10.1210/jcem.81.7.8675592)

27 Costenaro F, Rodrigues TC, Rollin GA, Ferreira NP \& Czepielewski MA. Evaluation of Cushing's disease remission after transsphenoidal surgery based on early serum cortisol dynamics. Clinical Endocrinology 201480 411-418. (https://doi.org/10.1111/ cen.12300) 
28 Igreja SC, Chahal HS, King P, Bolger GB, Srirangalingam U, Guasti L, Chapple JP, Trivellin G, Gueorguiev M, Guegan K et al. Characterization of aryl hydrocarbon receptor interacting protein (AIP) mutations in familial isolated pituitary adenoma families. Human Mutation 201031 950-960. (https://doi.org/10.1002/ humu.21292)

29 Daly AF, Vanbellinghen JF, Khoo SK, Jaffrain-Rea ML, Naves LA, Guitelman MA, Murat A, Emy P, Gimenez-Roqueplo AP, Tamburrano G et al. Aryl hydrocarbon receptor-interacting protein gene mutations in familial isolated pituitary adenomas: analysis in 73 families. Journal of Clinical Endocrinology and Metabolism 200792 1891-1896. (https://doi.org/10.1210/jc.2006-2513)

30 Preda V, Korbonits M, Cudlip S, Karavitaki N \& Grossman AB. Low rate of germline AIP mutations in patients with apparently sporadic pituitary adenomas before the age of 40 : a single-centre adult cohort. European Journal of Endocrinology 2014171 659-666. (https://doi. org/10.1530/EJE-14-0426)

31 Cazabat L, Bouligand J, Salenave S, Bernier M, Gaillard S, Parker F, Young J, Guiochon-Mantel A \& Chanson P. Germline AIP mutations in apparently sporadic pituitary adenomas: prevalence in a prospective single-center cohort of 443 patients. Journal of Clinical Endocrinology and Metabolism 201297 663-670. (https://doi.org/10.1210/jc.2011-2291)

32 Stratakis CA, Tichomirowa MA, Boikos S, Azevedo MF, Lodish M, Martari M, Verma S, Daly AF, Raygada M, Keil MF et al. The role of germline AIP, MEN1, PRKAR1A, CDKN1B and CDKN2C mutations in causing pituitary adenomas in a large cohort of children, adolescents, and patients with genetic syndromes. Clinical Genetics $2010 \mathbf{7 8}$ 457-463. (https://doi.org/10.1111/j.1399-0004.2010.01406.x)
33 Georgitsi M, Raitila A, Karhu A, Tuppurainen K, Mäkinen MJ, Vierimaa O, Paschke R, Saeger W, Van der Luijt RB, Sane T et al. Molecular diagnosis of pituitary adenoma predisposition caused by aryl hydrocarbon receptor-interacting protein gene mutations. PNAS 2007104 4101-4105. (https://doi.org/10.1073/pnas.0700004104)

34 Dinesen PT, Dal J, Gabrovska P, Gaustadnes M, Gravholt CH, Stals K, Denes J, Asa SL, Korbonits M \& Jorgensen JOL. An unusual case of an ACTH-secreting macroadenoma with a germline variant in the aryl hydrocarbon receptor-interacting protein (AIP) gene. Endocrinology, Diabetes and Metabolism Case Reports 20152015 140105. (https://doi. org/10.1530/EDM-14-0105)

35 Hernández-Ramírez LC, Gabrovska P, Dénes J, Stals K, Trivellin G, Tilley D, Ferraù F, Evanson J, Ellard S, Grossman AB et al. Landscape of familial isolated and young-onset pituitary adenomas: prospective diagnosis in AIP mutation carriers. Journal of Clinical Endocrinology and Metabolism 2015100 E1242-E1254. (https://doi.org/10.1210/ jc.2015-1869)

36 Katznelson L. Sustained improvements in plasma ACTH and clinical status in a patient with Nelson's syndrome treated with pasireotide LAR, a multireceptor somatostatin analog. Journal of Clinical Endocrinology and Metabolism 201398 1803-1807. (https://doi. org/10.1210/jc.2013-1497)

37 Hayashi K, Inoshita N, Kawaguchi K, Ardisasmita AI, Suzuki H, Fukuhara N, Okada M, Nishioka H, Takeuchi Y, Komada M et al. The USP8 mutational status may predict drug susceptibility in corticotroph adenomas of Cushing's disease. European Journal of Endocrinology 2016174 213-226. (https://doi.org/10.1530/EJE-150689)

Received 2 August 2017

Revised version received 27 September 2017

Accepted 3 October 2017 